\title{
Dynamics of storm-driven suspended sediments in a headwater catchment described by multivariable modeling
}

\author{
Milan Onderka • Andreas Krein • Sebastian Wrede • \\ Núria Martínez-Carreras • Lucien Hoffmann
}

Received: 24 August 2011 / Accepted: 29 January 2012 / Published online: 14 February 2012

(C) Springer-Verlag 2012

\begin{abstract}
Purpose Previous research has shown that the rate at which suspended sediment is transported in watercourses depends primarily on discharge $(Q)$ as the first-order control, but additional factors are thought to affect suspended sediment concentrations (SSC) as well. Among these, antecedent hydrological and meteorological conditions (e.g., rainfall depth and intensity, discharge prior to a runoff event and the duration of runoff events) may represent significant transport controlling mechanisms. Univariate models using $Q-$ SSC rating curves often produce large scatter and nonlinearity, because many of the hydrological and biotic processes affecting the dynamics of sediment are non-linear and exhibit threshold behavior. The simulation of such highly non-linear processes is therefore an elusive task requiring consideration of several interrelated controlling variables. The aim of this study was to identify the major hydrological and meteorological controls determining the dynamics of
\end{abstract}

Responsible editor: Ramon Batalla

M. Onderka • A. Krein $(\bowtie) \cdot$ S. Wrede $\cdot$ N. Martínez-Carreras •

L. Hoffmann

Department of Environment and Agro-biotechnologies,

Centre de Recherche Public - Gabriel Lippmann,

41, rue du Brill,

4422 Belvaux, Luxembourg

e-mail: krein@lippmann.lu

M. Onderka

Institute of Hydrology, Slovak Academy of Sciences,

Račianska 75,

83201 Bratislava, Slovakia

\section{S. Wrede}

Water Resources Section, Faculty of Civil Engineering and

Geosciences, Delft University of Technology,

P.O. Box 5048, 2600 GA Delft, The Netherlands
SSC during storm-runoff events and the magnitude of SSC in a headwater catchment in Luxembourg.

Materials and methods A parsimonious data-driven model (M5' modular trees) was used to simulate SSC in response to the identified controlling variables. Antecedent hydrometeorological variables (e.g., antecedent precipitation depths, antecedent precipitation indices, and a suit of hydrological data) were used as input variables.

Results and discussion Twenty-four-hour antecedent runoff volumes were determined as the major control explaining sediment depletion effects during high-flow periods, and a gradual decline of SSC as a runoff event progresses. The modeling results obtained by M5' trees were then compared to conventional power-law rating curves. The M5' model outperformed the rating-curve by being successful in describing the shape and magnitude of the analyzed sedigraphs. Therefore, we propose that incorporating antecedent hydrometeorological data into SSC prediction models may strongly enhance the accuracy of export coefficients. Two splitting criteria identified by the M5' model tree $(Q$ and antecedent runoff volume) were found and are discussed as possible thresholds responsible for the greatest nonlinearity in the $Q$ SSC relationship.

Conclusions Our study highlights the dominant antecedent hydro-meteorological conditions acting as the major controls on the magnitude of SSC during episodic events in the headwater Huewelerbach catchment in Luxembourg. For future application, it would be interesting to extend and test the data-mining approach presented in this paper to other catchments, where other controls on sediment transport may be identified.

Keywords Antecedent hydro-meteorological conditions . Huewelerbach catchment $\cdot$ M5' model trees $\cdot$ Suspended sediments $\cdot$ Storm event $\cdot$ Thresholds 


\section{Introduction}

Understanding mechanisms controlling the transport of solids from catchments is important for maintaining good water quality and the reduction of excessive soil erosion. Adequate knowledge of sediment transport phenomena has implications for river morphology, siltation of water reservoirs, transport of sediment-bound contaminants and soil erosion. Storm-runoff events are responsible for episodically increased sediment fluxes in surface waters. Suspended sediment may also facilitate the transport of nutrients (e.g., Bowes et al. 2003; 2009; Withers and Jarvie 2008; Drewry et al. 2009) and other chemicals adsorbed onto the surface of solid particulates (Owens and Walling 2002). Due to the multitude of environmental impacts of enhanced suspended sediment in aquatic systems, there is an imminent need to understand and identify the main factors controlling their release and subsequent transport by watercourses in order to propose appropriate remedial actions.

The extensive literature devoted to sediment export from catchments with contrasting physiography shows that there are three main categories of factors actively controlling suspended sediment mobilization and transport from catchments: (a) hydrological controls, often determined by the timing and magnitude of hydrograph components (e.g., overland flow, subsurface flow; Zabaleta et al. 2007); (b) meteorological forcings (e.g., air temperature, rainfall depth and intensity, intra-storm rainfall patterns; Seeger et al. 2004; NadalRomero et al. 2008); and (c) physiographic factors (e.g., catchment area, slope, heterogeneity of soil properties and the presence of preferential flowpaths; Schreier and Brown 2004), and land use (Buck et al. 2004).

Antecedent meteorological and hydrological conditions have been reported to determine both the hydrochemical and sedimentological response of catchments (Ollesch et al. 2005; Zabaleta et al. 2007; Francke et al. 2008; Ide et al. 2008; Macrae et al. 2010). Under dry conditions, the water storage capacity of a catchment is higher than under wet conditions when the surface and subsurface storage may be saturated. Antecedent moisture conditions actively control water flow paths (Christopher et al. 2008) and responsiveness of a catchment to precipitation (Buttle et al. 2001; James and Roulet 2009; Macrae et al. 2010). Antecedent moisture status of soils also determines the magnitude and the direction of the discharge $(Q)$-suspended sediment concentration (SSC) hysteresis loops (Butturini et al. 2006; Ide et al. 2008; NadalRomero et al. 2008). Sadeghi et al. (2008) highlighted the effect of antecedent soil dryness and soil water repellency as a possible mechanism for soil particle entrainment. In general, in many areas of the world, the longer antecedent dry periods persist, the more enhanced may be the transport of suspended sediment and particulate nutrients, due to the fact that prewetting a soil greatly decreases crusting, runoff and interrill erosion (Le Bissonnais and Singer 1992; McDowell and Sharpley 2002).

Many natural processes are non-linear, being "switched on and off" by certain thresholds in their controlling variables. As defined by Zehe and Sivapalan (2009), threshold behavior in hydrology is characterized by a rapid qualitative change of the dynamics of a process in response to the underlying controls. Two kinds of threshold behavior are recognized in environmental systems: thresholds at a process level (microscales, e.g., soil particle entrainment triggered by crossing a rainfall intensity threshold, or Hortonian flow); and threshold behavior observed as an abrupt change in the response of a complex system (e.g., catchment), which is too large to be treated in a fully deterministic way such as the threshold behavior at the process level (Zehe and Sivapalan 2009). Many hydrological processes are intermittent, because they are controlled by state variables switching from zero to a non-zero value (Buttle et al. 2001; Blöschl and Zehe 2005; Zehe and Sivapalan 2009). An example is storm-runoff response induced by rainfall with sufficient quantity and intensity, routed down slope to the channel network via different pathways. For example, subsurface storm flow is a special case occurring after a threshold of precipitation depth is exceeded; or Hortonian overland flow that occurs when rainfall intensities exceed a threshold when the ability of the soil to infiltrate water is exceeded (Zehe and Sivapalan 2009). Release of soil and sediment particles and erosion also exhibit threshold-like behavior (Sichingabula 1998; Ternat et al. 2008; Hicks et al. 2000). Traditionally, univariate mathematical formulations of the relationship between concentration and discharge are used for the calculation of export coefficients and sediment yield (Walling 1977; Horowitz 2003; Schleppi et al. 2006; Ide et al. 2007). However, due to the complexity of processes affecting sediment dynamics, such univariate relationships (e.g., log-log rating curves between discharge and concentration) are in most situations insufficient and result in large scatter (Walling 1977; Wood 1977; Sichingabula 1998; Alexandrov et al. 2007; Bača 2008). This variability is the consequence of non-linearities and threshold behavior in transport processes, as well as antecedent conditions, that control the sediment production and delivery in a unique way for each runoff event (Sichingabula 1998; Zabaleta et al. 2007; Ide et al. 2008). Given this complex character of sediment transport phenomena, a solution may be to develop specialized models to account for the particular sub-processes.

Recent studies report that data-driven models may offer a promising alternative for improving SSC $-Q$ relationships (Jain 2001). Data-driven models have been applied successfully in a number of applications in water resources. Cobaner et al. (2009) used neuro-fuzzy and artificial neural networks (ANN) to predict SSCs from the Mad River catchment, USA. Their study revealed that their data-driven models 
perform better than other models in daily SSC estimation. Tayfur (2002) developed an ANN model for sheet sediment transport and indicated that the ANN could perform as well as, and in some cases better than, the physically based models. Similar promising results have been achieved Kisi et al. (2006) and Mianaei and Keshavarzi (2010) with neuro-fuzzy techniques, and by Francke et al. (2008) and Lopez-Tarazon et al. (2011) with random forests. The main advantages of using data-driven models are their flexibility and ability to solve large-scale complex problems such as pattern recognition, non-linear modeling, classification, association, and control (Tayfur 2002).

Our approach is to use the modular data-driven model (M5' model trees) introduced by Quinlan (1992). It was originally devised to serve as a tool for discovering patterns (or structures) in datasets with the potential to provide insight into complex interactions between a number of interacting subprocesses for which separate specialized local models are built. Examples of M5' trees in environmental sciences include: Rusjan and Mikoš (2008) who used M5' models to predict and describe the dynamics of nitrate release from a forest catchment in relation to the seasonal aspect of hydrological and meteorological variables; Solomatine and Dulal (2003) who used model trees for rainfall-runoff modeling; Štravs and Brilly (2010) who used M5' to predict low flows; and Bhattacharya and Solomatine (2005) who used the model approach to define stage-discharge rating curves. Despite being more structurally comprehensive compared to other data-mining techniques (e.g., neural networks), M5' trees have not yet received full appreciation in the hydrological and sedimentological communities. To the best of our knowledge, M5' trees have not been used to model suspended sediment transport from headwater catchments. In this study, we used M5' modular trees as a tool to identify the main explanatory hydrological and meteorological variables controlling SSCs in a small headwater catchment in Luxembourg (Huewelerbach catchment).

The objectives of this paper are: (a) to determine the main explanatory variables (controls) affecting the magnitude of SSCs during storm-runoff events in response to antecedent hydro-meteorological conditions; and (b) to construct a parsimonious (empirical data-driven) model simulating SSC and explaining intra-event variability of SSC.

\section{Materials and methodology}

\subsection{Area of investigation}

The Huewelerbach experimental catchment studied in this paper is a humid temperate catchment located in the Grand Duchy of Luxembourg ( $\left.49^{\circ} 43^{\prime} 6.1^{\prime \prime} \mathrm{N}, 5^{\circ} 54^{\prime} 20.5^{\prime \prime} \mathrm{E}\right)$. The catchment has an area of $2.7 \mathrm{~km}^{2}$ and is located at the front of a geomorphological cuesta, on the transition zone between a sandstone plateau and the Attert valley, which is mainly composed of marly substrata (Fig. 1). The climate is pluvio-oceanic with mild winters and temperate summers.

During the investigation period, the annual precipitation averaged $744 \mathrm{~mm}$ producing an annual specific runoff of $189.2 \mathrm{~mm}$ (hydrological years 2005-2009). The average annual air temperature during the period of investigation was $8.7^{\circ} \mathrm{C}$. The elevation of the Huewelerbach catchment ranges from 280 to $392 \mathrm{~m}$ a.s.l. Land cover is composed of a mixed forest dominated by Fagus sylvatica L. (91.5\%) with smaller patches of Picea abies (L.) H. Karst. (7\%) and small grassland at the valley bottom. A network of unsealed forest roads is present in the catchment, which is a source of sediment during storm-runoff events (Martínez-Carreras et al. 2010a). The catchment is drained by a main stream channel that is fed by several smaller perennial streams which are mainly supplied by groundwater originating from sandstone springs located at the interface of the sandstone and marl formations (see Fig. 1). A thin alluvium layer extends across the main river course at the lower part of the catchment. A mixture of sandstones and marls form the base of this alluvium. Juilleret et al. (2012) showed that this lower part of the basin features complex soils and geology. Haplic Planosol (Ruptic, clayic) developed on the "Argiles de Levalois" geological formation is found in alternation with Stagnic Cambisol (Ruptic, Arenic) on the Rhetian sandstone of the "Formation de Mortinsart". The sandy hills present Hypoluvic Arenosol (Dystric) developed on the "Grès du Luxembourg" geological formation. Spectral properties of soils and sediments, suspended sediment transport dynamics, and suspended sediment properties and sources were studied by Martínez-Carreras et al. (2010a, 2010b, 2010c). Interception by forest litter has been investigated by Gerrits et al. (2010), while conceptualization and modeling studies of the water cycle were carried out by Van den Bos et al. (2004). Basic hydrological characteristics are indicated in Table 1 (the beginning of the hydrological year was defined as November 1st). During the study period, specific runoff ranged from 2.6 up to $76.61 \mathrm{~s}^{-1} \mathrm{~km}^{-2}$ with a median value of $51 \mathrm{~s}^{-1} \mathrm{~km}^{-2}$.

\subsection{Data collection and sampling protocols}

An extensive monitoring program in the catchment was initiated in 2002, and the catchment continues to be the subject of hydrological research. Precipitation and air temperature were measured in 15-minute intervals at a meteorological station located in the lower part (293 m a.s.l.) of the catchment (see Fig. 1). Given the position of the meteorological station and the size of our catchment, and the fact that the majority of rainfall events consisted of frontal storms with rather homogeneous spatial rainfall patterns, 


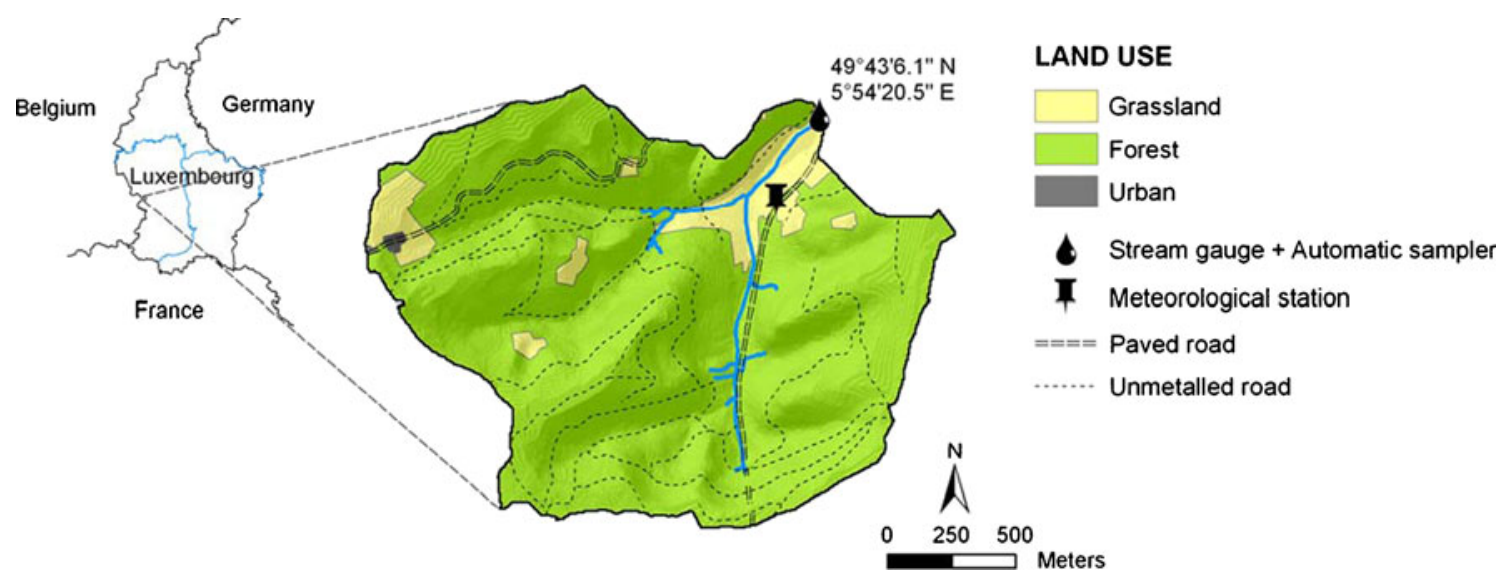

Fig. 1 Map of the Huewelerbach catchment, Luxembourg

rainfall recorded at this rain gauge (model 52203, manufactured by Young, Campbell Scientific Ltd.) can be considered representative of the entire catchment. The discharge measurement station is equipped with an electronic pressure sensor (ISCO 4120 flow logger) to measure water depth. Discharge is calculated by stage-discharge rating curves at 15-min intervals. Samples of stream water were regularly collected during storm-runoff events and more intermittently during low flows (Fig. 2). Sampling was mainly carried out by means of an automatic water sampler (ISCO 6712 FS) that was triggered at predetermined time steps or by flow conditions. Some grab samples were also collected. In order to assume a quasi flow-stratified sampling we tested the capability of the automatic water sampler to collect representative samples. SSC measurements obtained from flow-stratified sampling (i.e., manually) were compared to measurements obtained at the same time using the automatic water sampler at different flow conditions and SSCs $\left(R^{2}=\right.$ $0.83, n=5)$. In this way, we have been able to capture the temporal variability of SSC during changing flow conditions following rainfall and snow-melt events. The representativeness of the data was checked by plotting the flow duration curve (Fig. 3). The flow range encompassed all suspended sediment samples. The automatic sampler contained 24 1-1 plastic bottles connected to the stream via a hose. The amount of suspended matter was determined by filtering a known volume of water through pre-weighted
$1.2 \mu \mathrm{m}$ WHATMAN GF/C glass fiber filters (Millipore vacuum pump) and dried at $105^{\circ} \mathrm{C}$. In total, 346 suspended sediment samples were analyzed in the Huewelerbach catchment. Dates and characteristics of the captured events are indicated in Table 2.

Since the Huewelerbach catchment is a sandy catchment with most suspended sediment transported during high-flow periods triggered by precipitation, and our sampling strategy was focused on runoff events rather than baseflow conditions, both the sediment rating curves and the M5' models were applied only to samples taken during runoff events. This can be exemplified by one runoff event, which transported approximately $20 \%$ of the accumulated sediment load measured during all sampled events (sediment load estimated by integration of punctual SSC measurements). In addition, only a very small number of suspended sediment samples were taken during baseflow conditions $(n=55)$, hence we preclude that including them into the model would introduce a bias toward high-flow samples. The following filtering procedure (separation of baseflow) helped us to select only those samples that correspond to runoff events. The resulting rating curves and the M5' models are thus valid for high-flow conditions.

\subsection{Hydrograph separation}

For our further analysis, we focused on samples taken during storm-runoff events. The total discharge was thus separated

Table 1 Annual mean hydrological characteristics of rainfall depths, runoff components (baseflow and quickflow), and total runoff

\begin{tabular}{lrrrrrr}
\hline & 2005 & 2006 & 2007 & 2008 & 2009 & Average \\
\hline Annual rainfall depth (mm) & 583.8 & 735.8 & 906.0 & 946.0 & 548.8 & 744.1 \\
Annual total runoff (mm) & 148.3 & 141.9 & 198.6 & 258.3 & 199.0 & 189.2 \\
Annual baseflow (mm) & 119.0 & 110.6 & 152.1 & 202.0 & 159.3 & 148.6 \\
Annual quickflow (mm) & 29.4 & 31.4 & 46.5 & 56.2 & 39.7 & 40.6 \\
\hline
\end{tabular}

The total runoff coefficient ( $k=$ total runoff/precipitation) for the study period is $\approx 0.25$. Based on annual runoff, relatively dry years are the years 2005 and 2006 
Fig. 2 Hydrograph and sedigraph of the Huewelerbach catchment between 2005 and 2008
Huewelerbach Q, SSC (2005-2008)

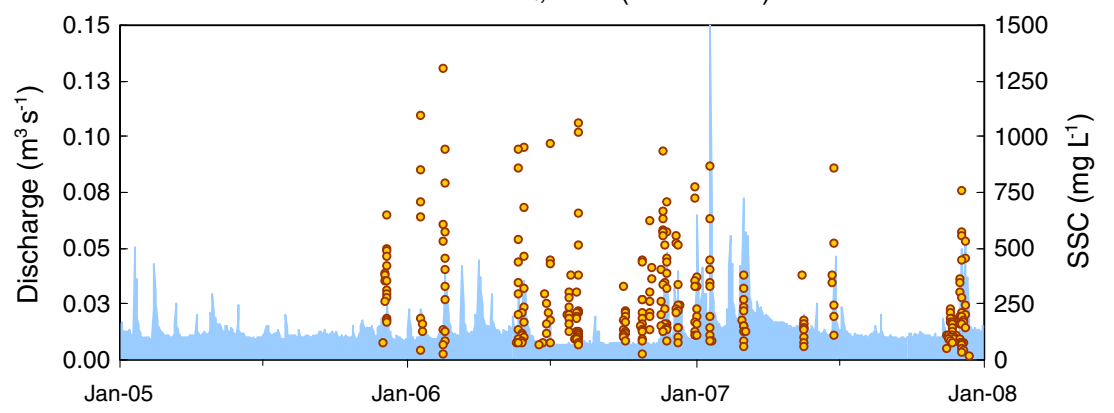

into its quick component (direct runoff) and slow component (baseflow), which is often considered to represent the groundwater. It is common engineering practice to define a quick component of the total runoff (quickflow) as that portion of the total runoff that is produced by rainfall and contributes immediately to the total streamflow during an event. The slow component of runoff (baseflow) is considered to be significantly delayed and is the less responsive portion of the storminduced runoff. Several automatic techniques are available for such quickflow separation (e.g., Nathan and McMahan 1990; Chapman and Maxwell 1996; Eckhardt 2005). In this study, we used the recursive low-pass digital filter (Eq. 1) introduced by Eckhardt (2005). This digital filter requires two parameters to be defined a priori: the recession coefficient $\alpha$, which can be assessed by analyzing hydrograph recessions; and the maximum value of the baseflow index $\mathrm{BFI}_{\max }$.

In order to minimize the subjective choice of the $\mathrm{BFI}_{\max }$ parameter, we used the recommended values for porous aquifers drained by a perennial stream-i.e. $\mathrm{BFI}_{\max }$ was set to 0.80 (Eckhardt 2005; 2008). The recession constant $\alpha$ was determined using the master recession curve based on the matching-strip method (Lamb and Beven 1997). The general form of the recursive filter is:

$\mathrm{BF}=\frac{\left(1-\mathrm{BFI}_{\max }\right) \alpha \mathrm{BF}_{k-1}+Q(1-\alpha) \mathrm{BFI}_{\max }}{1-\alpha \mathrm{BFI}_{\max }}$

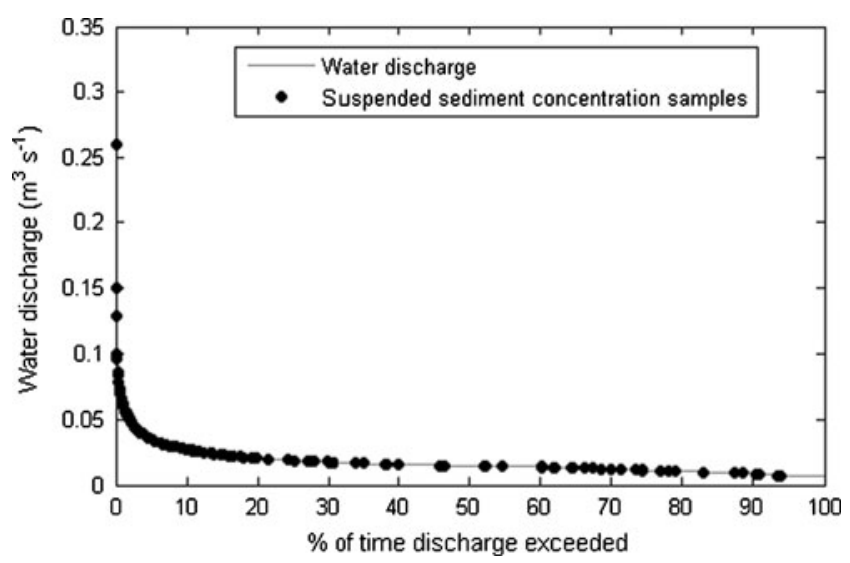

Fig. 3 Flow duration curve of the Huewelerbach catchment, December 2005 until February 2008. Black dots indicate the corresponding discharge for the suspended sediment concentration (SSC) samples where $\mathrm{BF}$ is the baseflow component of the total runoff (in millimeters per second); $\mathrm{BFI}_{\max }$ is the maximum baseflow index; $\alpha$ is the groundwater recession constant (nondimensional unit - assessed from the master recession curve using the whole hydrometric record of daily discharge), $Q$ is the total runoff (in millimeters per second); $\mathrm{BF}_{k-1}$ is baseflow at a previous time-step $k$. Eq. 1 is constrained to $\mathrm{BF} \leq Q$.

We defined the start and end of quickflow as the time when the quickflow component (determined as the difference between total runoff $Q$ and baseflow, i.e. $\mathrm{QF}=Q-\mathrm{BF}$ ) exceeded or dropped below $20 \%$ of the total discharge. As the selection of the $20 \%$ limit is rather subjective, the automatically separated events were visually inspected to discover possible inconsistencies. After separating the runoff into quickflow and baseflow for the analyzed hydrometric record (20052009), we processed the runoff depths into yearly statistics (see Table 1). The years 2005 and 2006 showed lower mean annual runoff depths, compared to the average from the whole period of observations 2005-2009. Low annual mean precipitation depths were found for 2005, 2006, and 2009 (below the mean precipitation depth of $744.1 \mathrm{~mm}$, see Table 1).

Based on the selected criteria $(\mathrm{QF}>20 \%$ of total discharge), the complete dataset of SSC was divided into two subsets, leaving 291 samples characterizing storm-runoff events and the rest (55 samples) characterizing low-flow conditions. Events with sequential multiple discharge peaks were classified as single multi-peaked events if QF did not drop below $20 \%$ between the occurrence of the individual peaks on the hydrograph.

Our aim was to analyze data covering various hydrological and meteorological antecedent conditions on SSC dynamics during high-flow conditions. For this reason, we analyzed the intra-annual variability of specific runoff from the catchment, which was calculated for the entire available period of data records (2005-2009). Mean annual specific runoff exhibited a distinct intra-annual variability (see Table 1). Specific runoff was calculated for the available hydrometric and pluviometric records (2004-2009). In 2005, the catchment received $160 \mathrm{~mm}$ less rainfall than the calculated average of $744 \mathrm{~mm}$ (see Table 1). In contrast, 2008 was the wettest year in terms of annual precipitation depth $(946 \mathrm{~mm})$, which also resulted in a greater amount of quickflow. 


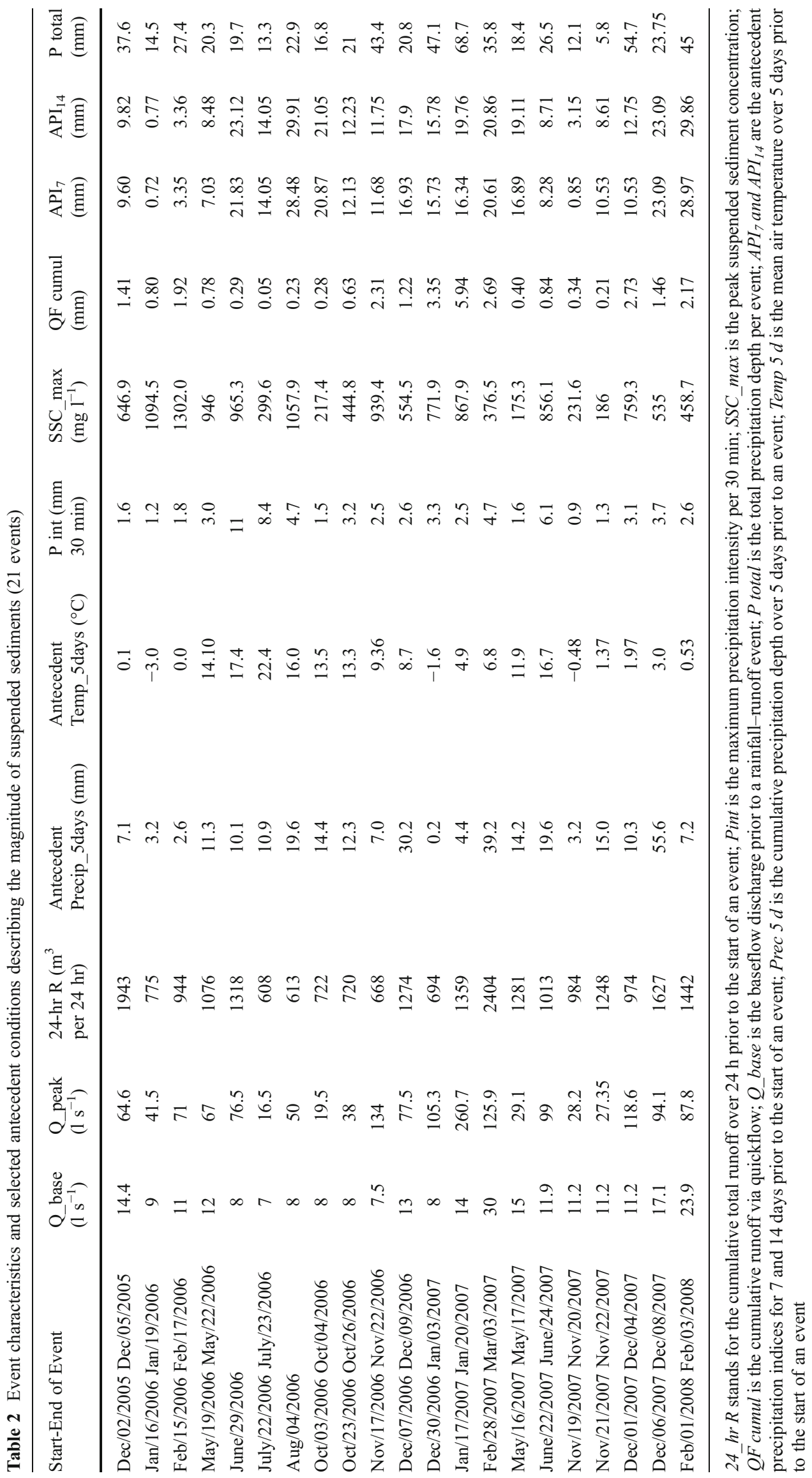




\subsection{Antecedent hydro-meteorological conditions}

Several researchers used the antecedent precipitation index to describe antecedent moisture conditions prior to a runoff event (e.g., Christopher et al. 2008). In this paper, the antecedent precipitation index (API) was calculated for 7 and 14 days prior to the start of an event as:

$\mathrm{API}_{n}=\sum_{i}^{n} \frac{P_{i}}{i}$

where $n$ is the number of days for which API is calculated starting from the beginning of an event; and Pi (in millimeters per day) is the total precipitation on the $i$ th day before the event. API for 7 and 14 days are listed in Table 3. The 5-day cumulative precipitation depth (Prec 5 d) was selected as an additional surrogate of antecedent wetness conditions.

\subsection{M5' model trees}

Due to the complex character of SSC transport, a solution may be to develop specialized modular models to account for the particular sub-processes, instead of developing a global model. Our approach was to use modular datadriven models (M5' model trees; Quinlan 1992). The fundamental principle of model trees resides in splitting a training data set into several subsets, so that the input data space of independent variables is divided into a set of smaller regions for which locally specialized models are developed (Solomatine and Siek 2006; Solomatine et al. 2008). The splitting procedure is done progressively, which results in a hierarchical tree-like structure with the splitting rules placed in non-terminal nodes, and linear (regression) models presented for each terminal leaf. M5' models are constructed by the divide-and-conquer principle, i.e., the set of training data points is either instantly associated with a leaf, or used as a criterion for splitting the training cases into subsets - which is repeated recursively to all the subsequent subsets (Quinlan 1992). Standard deviation of the independent variable is used as a splitting criterion in deciding which attribute is most appropriate for splitting the whole training dataset (Eq. 3):

$\mathrm{SDR}=\operatorname{SD}(T)-\sum_{i} \frac{\left|T_{i}\right|}{|T|} \times \operatorname{SD}\left(T_{i}\right)$

where $T_{i}$ is for the partial datasets that result from splitting the node according to the chosen attribute; $\operatorname{SD}\left(T_{i}\right)$ is the standard deviation of a data subset $\left(T_{i}\right)$ that resulted from splitting the node according to the chosen attribute; and $\operatorname{SD}(T)$ is the standard deviation of the instances reaching that node. The splitting process is an iterative process and terminates when either the instances reaching a node vary only slightly (in terms of the standard deviation), or there are only a few instances left. Then, the attribute that contributes to a maximum error reduction is selected for splitting at a node (Quinlan 1992; Witten and Frank 2005). In addition, a multivariate linear model is constructed for each leaf containing a subset of attributes. The use of linear equations is the fundamental difference of M5' trees compared to the regression of classification trees that provide only an average numerical value (regression trees) or a class value (classification trees) for each terminal note of a constructed tree. The M5' algorithm used in this paper is implemented in the Weka ${ }^{\circledR}$ 3.4.16 software (developed at The University of Waikato, New Zealand). Slight changes in the training data set may result in selection of a different attribute for a split or at a particular node - which might give rise to structurally unstable trees (Witten and Frank 2005). The instability problem of all tree classification schemes is that small change in input training samples may cause dramatically large changes in the position of splits (a split that was slightly inferior to the selected splits becomes slightly superior). Hence, once a different split is selected, the sub-tree evolving from that node may be very different from the original one ( $\mathrm{Li}$ and Belford 2002). The stability of the resulting tree structure was examined by bootstrapping the original dataset and growing a tree for each bootstrapped sample. For this, we used the bagging option in Weka 3.4.16.

Based on previous research on possible mechanisms controlling sediment transport from catchments, the following candidates were considered as input variables: instantaneous discharge; quickflow; precipitation; air temperature; lagged/
Table 3 List of variables used to construct the M5' model

$n$ denotes the time over which the particular variable was calculated

\begin{tabular}{lll}
\hline Description & Abbreviation & Unit \\
\hline Instantaneous discharge & Qinst & $\left(\mathrm{m}^{3} \mathrm{~s}^{-1}\right)$ \\
Discharge lagged by n minutes & $\mathrm{Q} \_$n $\mathrm{min}$ & $\left(\mathrm{m}^{3} \mathrm{~s}^{-1}\right)$ \\
Rate of change in discharge & $\mathrm{dQ} / \mathrm{dt} \_\mathrm{n}$ & $\left(\mathrm{m}^{3} \mathrm{~s}^{-2}\right)$ \\
Cumulative antecedent precipitation depth over n previous hours & Psum_n_hr & $(\mathrm{mm})$ \\
Average air temperature over previous hours & T_air_n_hr & $\left({ }^{\circ} \mathrm{C}\right)$ \\
Cumulative antecedent runoff volume over n previous hours & R_n_hr & $\left(\mathrm{m}^{3}\right)$ \\
Antecedent precipitation index for 7 and 14 days & API 1,14 & $(\mathrm{~mm})$ \\
\hline
\end{tabular}


cumulative antecedent characteristics (i.e., lagged values of discharge and quickflow, antecedent precipitation depth, antecedent runoff depth, average antecedent air temperature); antecedent precipitation indices for 7 and 14 days; and baseflow prior to the start of a runoff event. The selection of input variables for the M5' model was based on the trial-and-error basis, i.e., omitting those variables that did not contribute to, or even decreased, the performance of the model. Our decision to retain or discard a variable was based on the coefficient of correlation and root mean square error (RMSE) of observations and the output of the M5 model as selection criteria. After this initial variable selection, we constructed a single model (for the retained variables, see Table 3). The instantaneous quickflow and precipitation did not improve the predictions, in fact, the results were worse, and hence these two variables were discarded. Antecedent hydrological conditions were expressed as antecedent runoff volume. Ide et al. (2008) suggested in their study on particulate phosphorus that incorporating the rate of change in discharge as an explanatory variable may explain sudden pulsing of particulates on the rising limb of hydrographs. Assuming that the same premise could be held for suspended sediment (due to the existence of a strong link between particulate phosphorus and suspended sediment), we tested the performance of our M5' model with the rate of change in discharge. Air temperature was chosen as a candidate variable because it was reported to modify surface runoff generation and also the erodibility of soil, especially during snow-melt and ground freezing periods (Ollesch et al. 2005).

\subsection{Power-law functions}

Power-law relationships between suspended sediment and other water-borne substances are a well-established practice for expressing a simplified, basically univariate, relationship (Horowitz 2003; Alexandrov et al. 2007). Rating curves are generally obtained by least squares regression on logarithmic transformed data (Asselman 2000) or regression using a non-linear least square fitting with and without an additive constant term. In this study, we compare the performance of both $\log -\log$ and non-linear rating curves with the M5' model. As the power-law function is a univariate approach (Eq. 4), i.e., factors other than discharge are inherently not taken into account, the general form of the power-law rating curve is:

$y=b Q^{c}$

where $b$ and $c$ are coefficients fitted to the measured data after $\log -\log$ transformation or non-linear fitting by the NelderMead downhill simplex method with RMSE as the objective function.

\section{Results}

3.1 Magnitude of suspended sediment concentration in response to hydro-meteorological conditions

In order to explore the factors responsible for the range of SSCs, maximum concentrations of suspended sediments during the sampled storm-runoff events were statistically examined by cross-correlation analysis with respect to the hydrological and meteorological conditions. With this analysis, we sought to get an initial assessment of which, if any, of the selected hydro-meteorological conditions affect sediment transport. Each runoff event was described by the following hydrological and meteorological variables (also see Table 2$)$ : maximum rainfall intensity over $30 \mathrm{~min}(P$ int); peak discharge ( $Q$ peak); discharge at the beginning of the event ( $Q$ base); cumulative runoff via quickflow $(Q F$ cumul); cumulative runoff via baseflow (BF cumul); total precipitation depth ( $P$ total); antecedent precipitation indices calculated according to Eq. 2 for 7 and 14 days prior to the start of an event (API7 and API14); cumulative precipitation depth for the five previous days (Prec $5 d$ ); and mean air temperature over the five previous days (Temp $5 d$ ). As an additional characteristic describing the hydrological regime of the stream prior to sediment sampling, the cumulative total runoff was calculated for $24 \mathrm{~h}$ prior to the start of an event ( $\left.R \_24 h r\right)$. Cross-correlation analyses (Fig. 4) revealed that SSC peaks during the identified events were positively related $(R=0.37, p<0.05)$ to peak discharge $(Q$ peak), yet only a poor correlation was found with maximum rainfall intensity $(P$ int $)(R=0.16 ; p<0.05)$. On the other hand, SSC peak magnitudes were negatively correlated with the suite of antecedent precipitation indices $\mathrm{API}_{7}, \mathrm{API}_{14}$, the 5 -day antecedent precipitation depth (Prec $5 d$ ) and discharge at the beginning of the rising limb of the hydrograph ( $Q$ base) with Pearson correlation coefficients of -0.2 , -0.18 , and -0.265 , respectively. This could suggest that sources of suspended sediment were depleted after humid periods. Suspended sediment peaks were negatively correlated with the 24-h runoff volume $\left(R \_24 h r\right)$ with $R=-0.23$, also suggesting depletion of sediment sources during previous runoff events or periods of high baseflow.

\subsection{Intra-event conditions controlling suspended sediment concentrations}

A total of 26 storm events was captured between the years 2005 and 2009 (see Table 2). These events covered a broad range of hydrological and seasonal conditions (broad range of discharge, and both dormant and growing seasons), as well as relatively dry and wet hydrological conditions (see Table 2). The maximum peak discharge during the event of February 2006 was $711^{-1}$ with the maximum SSC reaching 
Fig. 4 Maps of pair-wise correlation coefficients between maximum event-based suspended sediment concentration (SSC_max) and selected explanatory variables (as indicated in Tables 2 and 3). The scale represents the correlation coefficient $-1<R<1$. The variables have been rearranged using the k-nearest neighbor clustering algorithm to project the highly correlated variables along the main diagonal

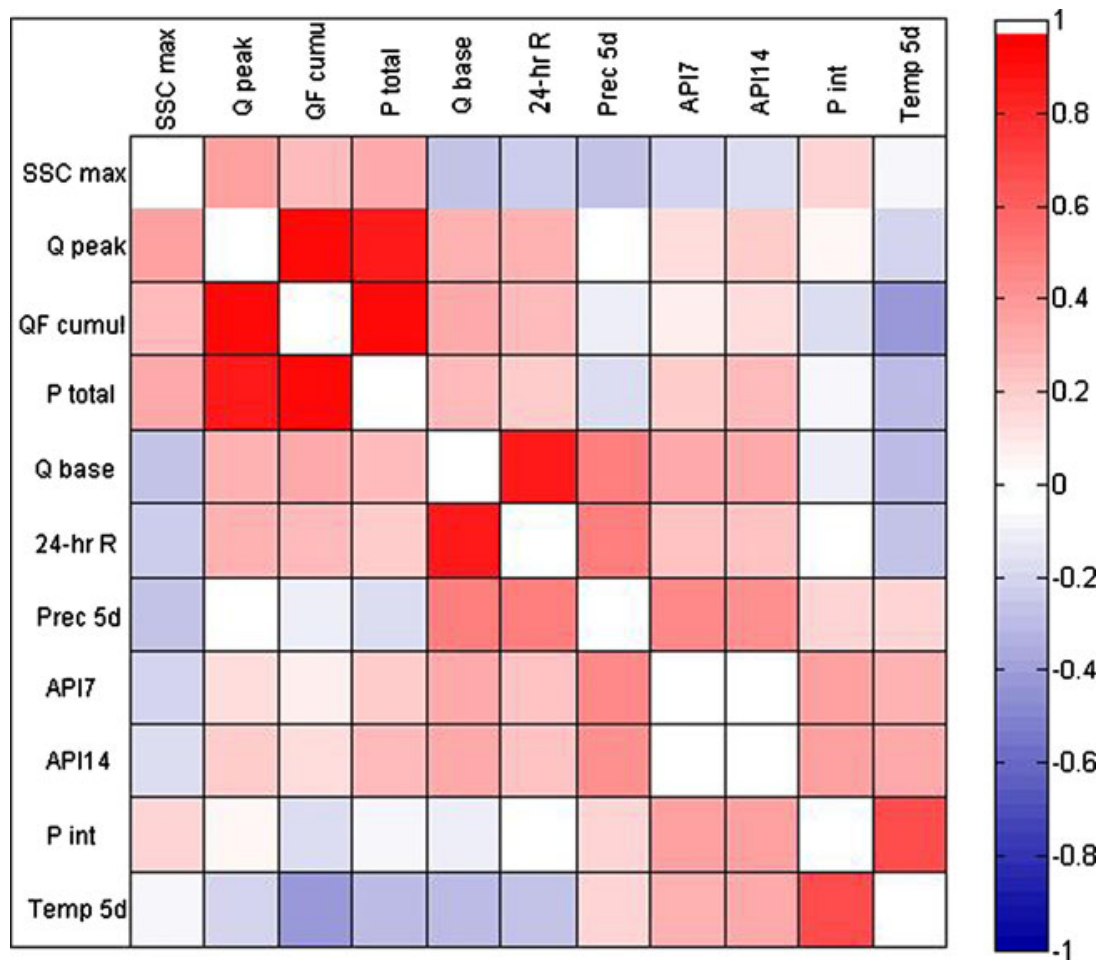

$1302 \mathrm{mg} 1^{-1}$. SSC usually peaked before discharge or occurred almost coincidently with discharge. This phenomenon has been previously described as a common feature indicating depletion of available sediment sources on the streambed without sufficient replenishment from hillslopes (Walling 1977; Zabaleta et al. 2007). An example of the depletion effect is the double-peaked event in December 2005 which was accompanied by a lower SSC peak at the second runoff episode (see Fig. 7). A similar pattern was observed during the event in February 2006 (see Fig. 7).

\subsection{Results from M5' models}

An M5' model was created to simulate concentrations of SSC in response to the chosen input variables of antecedent hydrological and meteorological conditions prior to the analyzed events (see Table 3). The resulting M5' models indicated as terminal nodes with linear models are listed in Table 4 and are visualized in the form of a tree structure in Fig. 5. The first major split in the tree is placed on instantaneous discharge $(Q)$, being followed by antecedent runoff volume integrated over the previous $24 \mathrm{~h}$ (R_24hr). The instantaneous discharge splits the entire dataset into two separate regions: $Q \leq 321 \mathrm{~s}^{-1}$ and $Q$ $>321 \mathrm{~s} \mathrm{~s}^{-1}$. For the lower branches of the tree, R_24hr and $Q$ were identified as subsequent splits on the tree hierarchy. The cumulative precipitation depth over the previous $48 \mathrm{~h}$ (P_48hr) is placed as the lowest split in the tree. Due to the reported instability issues of recursively partitioning algorithms (Li and Belford 2002), we performed a simple statistical analysis on the trees obtained from a bootstrapped dataset.
Resampling the original dataset 100 times, the resulting trees were visually examined for consistency in positioning of their branches (splits). Discharge $(Q)$ appeared at the root split in $93 \%$ of bootstrapped samples with a mean splitting value $31.409 \pm 2.126 \mathrm{~s}^{-1}$ ( \pm St. Dev). The 24-h cumulative runoff volume (R_24) appeared in $83 \%$ of the bootstrapped samples as a secondary split below the primary split of discharge $(Q$ $>321^{-1}$ ), with a mean splitting value of $2271.58 \pm$ $304.308 \mathrm{~m}^{3} / 24 \mathrm{~h}$. With such a high occurrence of $Q$ and R_24 on the primary and secondary splits (and relatively low dispersion around their mean values), we suggest that these two variables constitute rather stable splits with stable splitting values. The remaining splits (with lower positions on the tree hierarchy; see Fig. 5) were inconsistent in their values as well the selected splitting variables. We suggest that only splits that are located close to the tree root can be considered reliable and hence stable.

With the terminal equations obtained from the M5' model tree, we attempted to simulate the response of SSC to the considered explanatory variables. In Fig. 8, we plotted measured SSC along with simulated SSC by the M5' algorithm that was color-coded according to the locally specialized equations indicated in Table 4. For comparison, concentrations calculated from the linear fit on log-transformed data and non-linear fit to Eq. 4 were also plotted in Fig. 8. In general, the M5' model outperformed the rating curves, in terms of describing the shape of sedigraphs, and partially also the range of measured concentrations. For the December 2005 event (see Fig. 8h), the M5' model described the pronounced decline in SSC during the second peak 


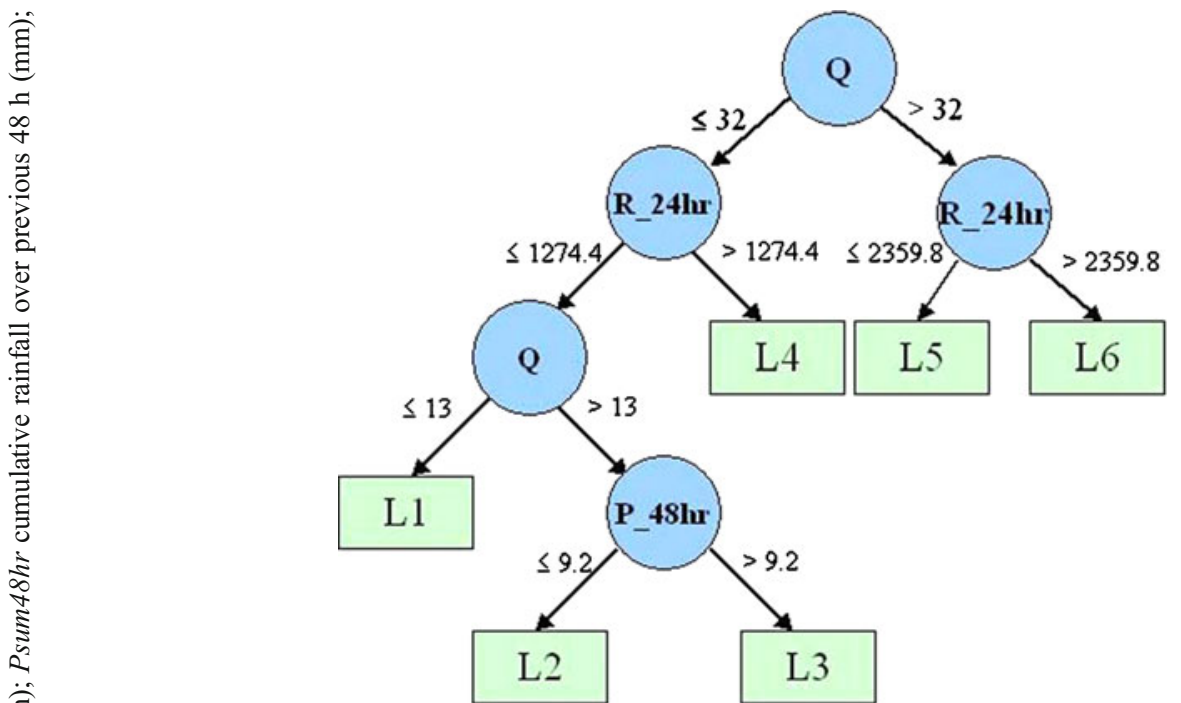

Fig. 5 Tree structure of the M5' model proposed for suspended sediment concentration (SSC). The nomenclature is the same as in Table 3. Terminal nodes (rectangulars $L 1-L O$ ) indicate the local linear specialized models (Table 4)

reasonably well. The event of January 2006 (see Fig. 8g) was also simulated with a reasonable accuracy. The performance of the power-law rating curves was poor $\left(R^{2}=0.2\right.$, RMSE $\left.=202 \mathrm{mg} \mathrm{l}^{-1} ; p<0.05\right)$, as it was not able to explain either the SSC peak preceding peaks of discharge, or gradual decrease of SSC during the sequence of two peaks encountered during the December 2005 event. Similarly, the shapes of the remaining sedigraphs were better described by the M5' tree than by the rating curves. The overall performance of the M5' models and the simulations of SSC by the rating curves can be visually inspected in scatterplots between measured and simulated SSC (Fig. 6). Both the linear fit to $\log$-log-transformed data (see Fig. 6a) and the non-linear fit (see Fig. 6b) severely overestimated SSC values in the lower range, and underestimated higher values. On the other hand, the M5' model yielded quantitatively better results in terms of the RMSE and mean absolute error (MAE) compared to the conventional rating curve approach (see Fig. 6c).

Although the M5' model performs better than the conventional rating curve (higher SSC concentrations are closer to the 1:1 line in Fig. 6), there is still a considerable scatter. As sediment concentrations in natural channels are also affected by other factors such as the sudden collapse of stream banks or sampling uncertainty, this residual scatter of data points on the $\mathrm{SSC}-Q$ plots is unavoidable.

\section{Discussion}

Antecedent hydro-meteorological conditions have been shown to actively determine the magnitude of SSCs. For 

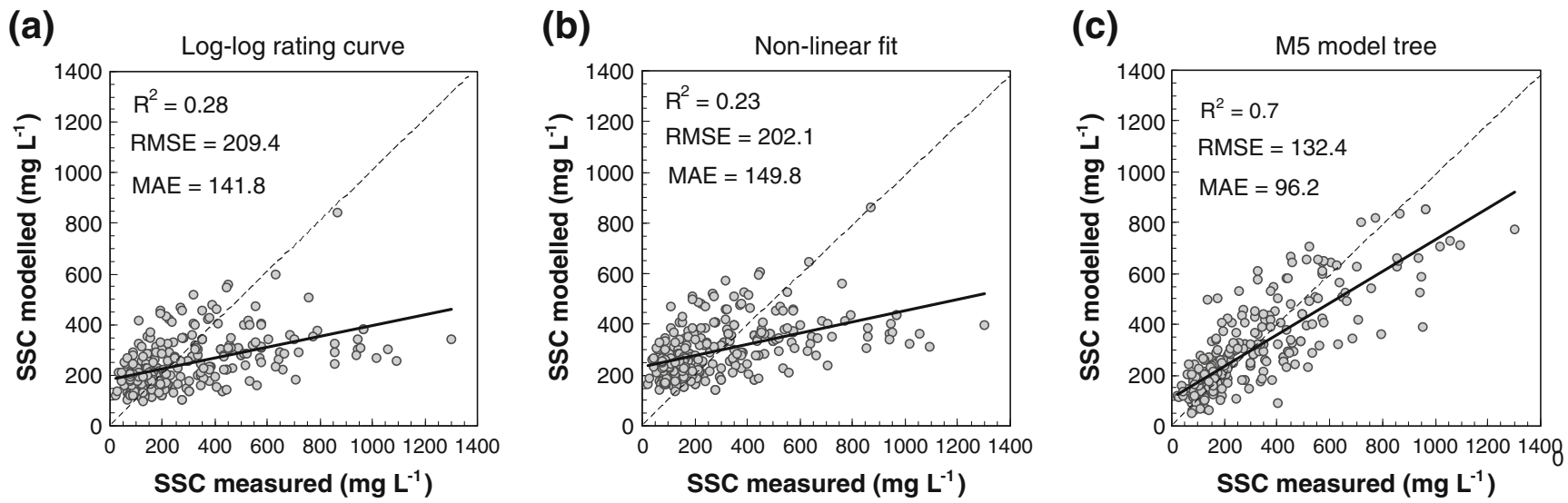

Fig. 6 Comparison of measured and simulated suspended sediment concentrations (SSC) by means of: a log-log rating curve; $\mathbf{b}$ non-linear fit; and c M5' model tree. RMSE (in milligrams per liter) is the root mean squared error, and MAE (in milligrams per liter) is the mean absolute error

the analyzed storm-runoff events (see Table 2), the following antecedent hydro-meteorological conditions negatively affected the overall magnitude of SSC maxima (peaks): antecedent precipitation depth $(R=-27, p<0.05)$; 24$\mathrm{h}$ runoff volume (R 24hr) with $R=-0.23$; and antecedent precipitation indices $\left(\mathrm{API}_{7}\right.$ and $\left.\mathrm{API}_{14}\right)$ with $R=-0.2$ and 0.18 , respectively. The negative correlations suggest that sediment sources (in the channel itself or from nearchannel areas) become depleted during previous runoff events or periods of high discharge. The wetter a catchment is prior to a runoff event, the lower are the availability of erodible sediment sources and SSCs during successive runoff periods. These results are in agreement with previous studies examining the affect of antecedent soil dryness and rainfall history on sedimentological response of catchments (Butturini et al. 2006; Ide et al. 2008; Nadal-Romero et al. 2008; Sadeghi et al. 2008).

But do antecedent hydro-meteorological conditions also affect the intra-event variability of suspended sediments? We attempted to provide an answer to this question by reconstructing and sequencing the analyzed runoff events using M5' model trees. The structure of the model tree provides several advantages over global models (rating curves) using the entire dataset for constructing a relationship between SSC and an explanatory variable. Global models often produce large scatter (Sichingabula 1998; Asselman 2000) and, indeed, scatterplots between $Q$ and measured SSC in Fig. 6a-b confirm this general observation in the Huewelerbach catchment. Several problems have been recognized in respect to the accuracy of the fitted log-log curve. Scatter around the regression line is caused by variations in sediment supply due to antecedent conditions and differences in sediment availability. As noted by Asselman (2000), some researchers have attempted to find a physical meaning to the regression coefficients. For instance, the $b$-coefficient could represent the erosive power of the stream or an indication of the extent to which new sediment sources become available when discharge increases, while the erodibility of the soils would be represented by the $a$-coefficient. We used a modular approach to describe the relationship between $Q$ and other explanatory variables, which allowed us to identify the influence of the individual variables (or controls) on the simulated SSCs (see Fig. 5). We speculate that despite their empirical nature, the splitting criteria identified by the M5' model trees have the potential to be physically interpreted and related to plausible thresholds and dynamically changing controls affecting the behavior of SSC mobilization and the subsequent transport through the draining network to the catchment outlet. The M5' model identified the instantaneous discharge (Qinst) and runoff volume (R_24hr) as the primary and secondary splitting criteria on the $\mathrm{M}^{\prime}$ tree that was developed to simulate SSC (see Fig. 5). The scatterplot in Fig. 7 shows two regions separated by Qinst and R_24hr. At this stage, it is uncertain if the splits define true physical thresholds, but the exact value of the split for R_24 $\left(2,360 \mathrm{~m}^{3}\right.$ in $\left.24 \mathrm{~h}\right)$, as identified by the M5' model, is a breakpoint at which the system might undergo an abrupt change in the sedimentological response. With R_24hr dropping below $2,359.8 \mathrm{~m}^{3}$ in $24 \mathrm{~h}$ (terminal node L5 in Fig. 5), sediment were probably still available in sufficient quantities to be mobilized and transported by the increased discharge. However, for runoff volumes R_ $24 \mathrm{hr}$ exceeding $2,359.8 \mathrm{~m}^{3}$ in $24 \mathrm{~h}$, there may have not been enough sediment stored on the channel bed or along the channel banks, and hence SSC increased less steeply with increasing $Q$. The runoff volume $\mathrm{R} \_24 \mathrm{hr}$ thus may explain the depletion of sediment sources in the channel and near-stream areas after long-lasting events or a sequence of short-lived events, as we observed for the events in December 2005 and November 2006 (Fig. 8g, h) with a gradual decline in SSC on successive runoff episodes; second SSC peaks are lower than SSC peaks on the first runoff episode. It is important to note that at the same time, $\mathrm{R} \_24 \mathrm{hr}$ was identified as a regressor in the terminal leaf equations among other input variables, which may explain the progressive declining sediment availability in the channel with long-lasting events such as the one in January 


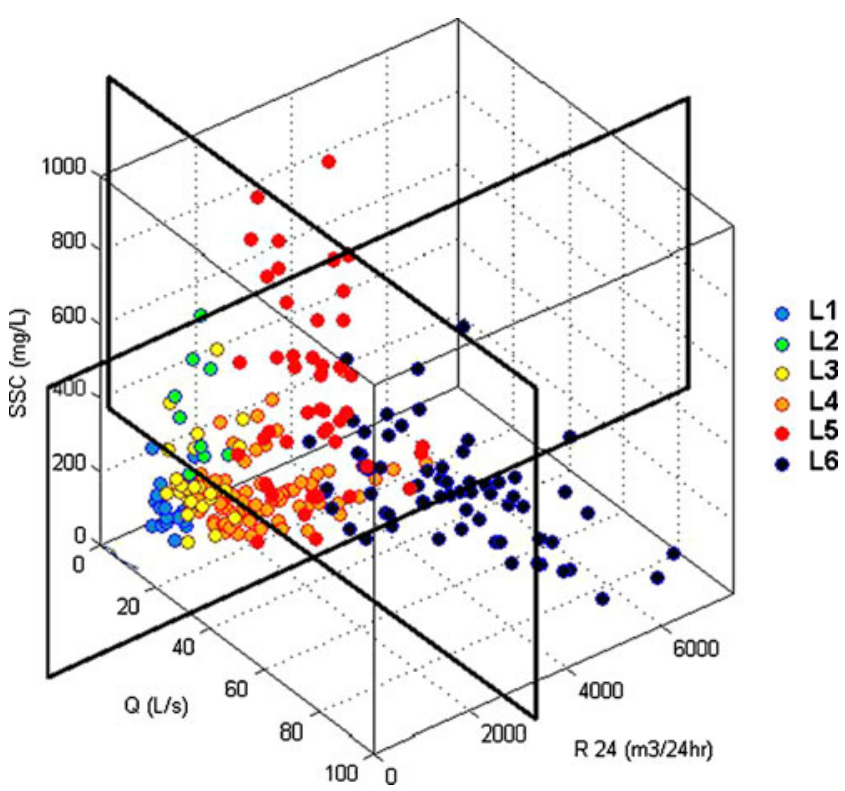

Fig. 7 3-D scatterplot of discharge $(Q)$, antecedent runoff volume (R 24) and measured suspended sediment concentration (SSC) at the outlet of the Huewelerbach catchment. Data points are color-coded according to their position on the model tree (see Fig. 4). The planes separate regions defined by the primary split $Q\left(321 \mathrm{~s}^{-1}\right)$ and secondary split R_24 (2359.8 $\left.\mathrm{m}^{3} / 24 \mathrm{~h}\right)$

2007. Events exhibiting a longer duration or a sequence of short events often manifest in a gradual decrease of SSC, and hence the incorporation of the variable R_24hr into the linear equation (see Table 4) appeared to be appropriate. In situations when the hydrograph was composed of multiple peaks with only short inter-event periods, the sediment load can be regarded as under-capacity load, i.e. SSC were limited by the supply of sediment rather than the hydraulic ability of the $Q$ to transport them. However, the rate of change in discharge $(\mathrm{d} Q /$ $\mathrm{d} t$ ), as another possible physical control of $Q$ on sediment remobilization (Ide et al. 2008) did not appear anywhere in the resulting model trees. Probably, overall catchment response is not fast enough to explain an increase in SSC on the rising limb. We believe that the incorporation of the rate of change in $Q$ as a physical control may be more relevant in flashier catchments. Antecedent temperature did not appear in any of the splits of the M5' tree in contrast to our initial assumption that it might exert a significant threshold mechanism controlling the sediment transport, separating winter periods with frozen ground or snow-melt events and the rest of the year.

The first major split in the M5' tree was placed on instantaneous discharge $(Q)$, and the antecedent runoff volume integrated over the previous $24 \mathrm{~h}$ (R_24hr). Here, we hypothesize that the R_24hr runoff volume determines the extent to which the available sources of sediments have been depleted during previous high-flow conditions that are usually accompanied with episodic runoff events or periods of elevated baseflow.

We suggest that identifying true physical thresholds in highly complex systems (e.g., catchments) is most often hindered by interfering responses caused by several subprocesses that interact in time and space. As the regions separated by the splits of the M5' model are not particularly sharp (see Fig. 6), we can only assume that the threshold behavior at a process level (e.g., remobilization of streambed sediments by scour triggered by a discharge threshold) might exist in our catchment. De Sutter and Verhoeven (2001) and Petticrew et al. (2007) conducted artificial flood experiments to evaluate the influence of a transient regime on the transport efficiency of the flow in a headwater catchment (the Olewiger catchment, Germany). Their hydraulicdriven experiments suggest the existence of a threshold in shear-stress velocity on SSC. Also Evans et al. (2003) described "entrainment thresholds" for sediments in relation to discharge. Interaction of sub-processes encountering threshold behavior are often visible as a non-linear response of a complex system due to superposition of various signals (Zehe and Sivapalan 2009). Therefore, a single process threshold may not always be readily discernable in the overall response of a complex system. Since the streambed of the Huewelerbach creek is mostly sandy, the suspended sediments are likely to result from entrainment of sediment particles from the bed following scour induced by a threshold discharge, but more investigation is needed to support this hypothesis.

In general, the M5' model proved to be relatively successful in simulating the shape of the analyzed sedigraphs. In contrast, the power-law function was not capable of explaining the different concentrations on the rising and the recession limbs. The M5' model outperformed the power-law rating curve despite not being able to completely explain the variation of SSC during the analyzed events (see Fig. 6). The dynamics of suspended sediments is a process governed by antecedent meteorological and hydrological conditions. The overall dynamics of suspended sediments during storm-runoff events are primarily determined by discharge, but antecedent hydrological conditions determine the availability of sediment sources for mobilization and transport during subsequent runoff events. The antecedent runoff regime, in particular the runoff volume over $24 \mathrm{~h}$ was shown to explain well the observed decline of SSC during successive events.

The rationale of using antecedent runoff volume to account for sediment exhaustion is based on the fact that the bed sediment storage may become depleted after a runoff event, whereupon there may not be much sediment available for subsequent remobilization during the next runoff event. In the literature, various shapes of hysteresis have been reported (e.g., Walling 1977; Zabaleta et al. 2007), but the fact the SSC peaks precede $Q$ peaks (see Fig. 8), generating a clockwise hysteresis in our catchment, is therefore most probably caused by a depletion of sediments deposited in the channels or near-stream areas. We suggest that the 
(a)

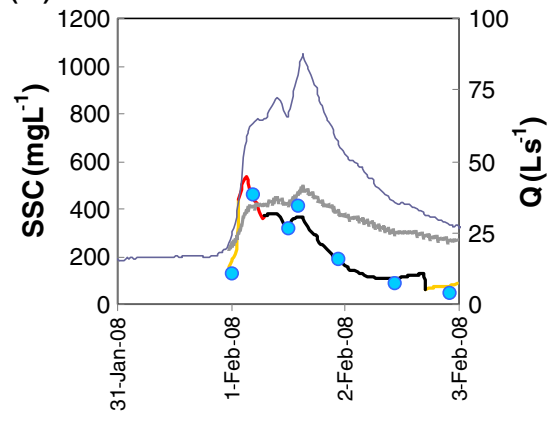

(d)

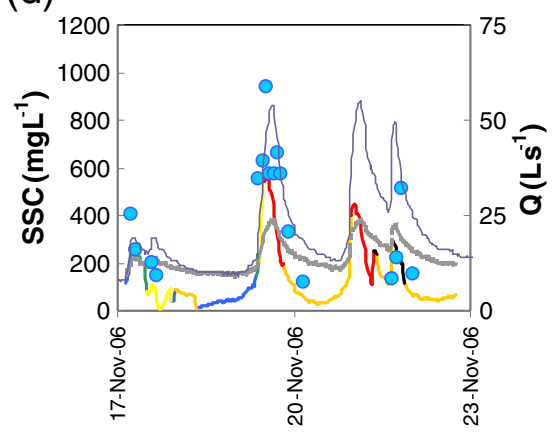

(g)

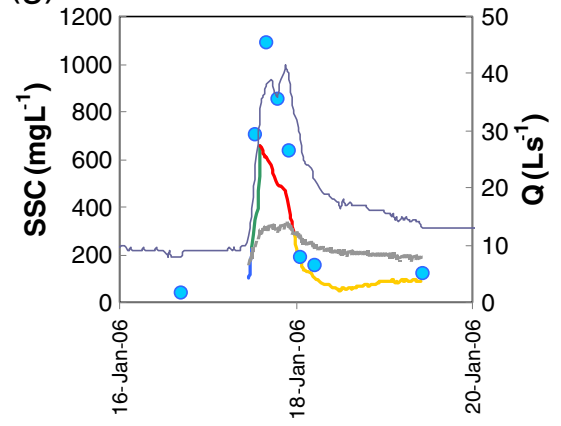

(b)

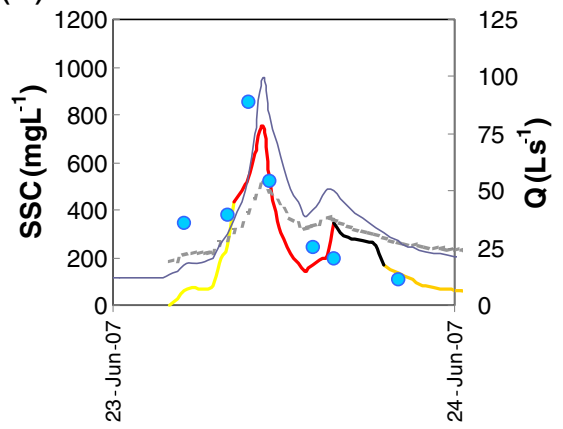

(e)

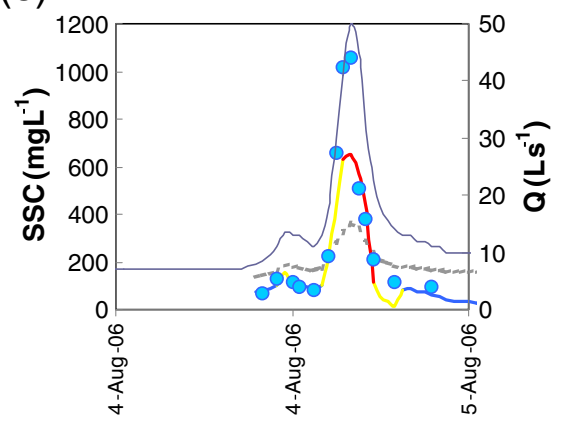

(h)

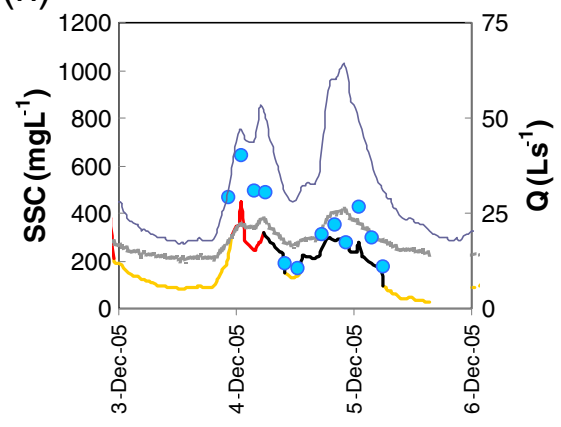

(c)

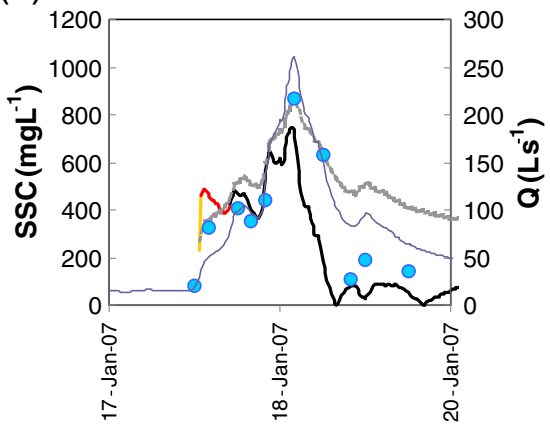

(f)

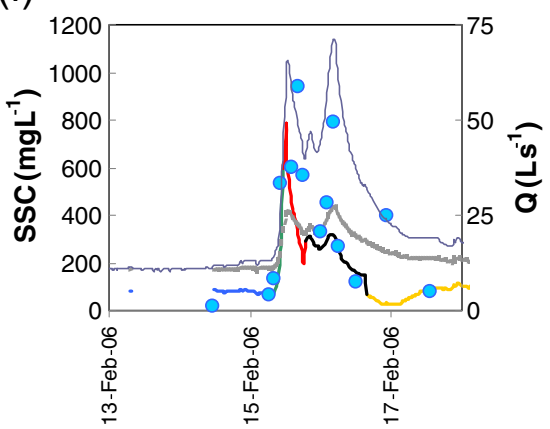

Fig. 8 Comparison of measured suspended sediment concentrations (SSC) with modeled concentrations by the M5' model and the powerlow rating curve (linear fit to log-transformed data). SSCs simulated by

variable of antecedent runoff volume should be incorporated into models since it can explain the sediment exhaustion effect in catchments where sediment sources originate especially in stream bed or stream banks.

Since the relationship between $Q$ and SSC exhibits a nonlinear behavior, modular modeling is of high relevance for imputing concentration during missed storms (due to equipment failure or unavailability or with insufficiently dense sampling intervals) and subsequent improvement of export coefficients (sediment yield). Moreover, the traditional approach of relating a functional relationship between $Q$ and SSC (rating curves) has been shown to substantially underestimate high SSC and overestimate low SSC (Horowitz 2003). Our results confirm this widely observed fact (see the M5' tree are color-coded according the corresponding linear models L1-L6 (see Table 4)

Fig. 6a-b). Modular models may overcome these shortcomings by devising specialized models explaining subprocesses on a local level. Given the fact that the performance of modular trees was found to be better than the loglog rating curve, using the presented modular approach may resolve issues of unreliable estimates of sediment yield.

Suspended sediment transport in the Huewelerbach catchment is a precipitation driven process and highly linked to sediment supply. It would be interesting to test the modular approach presented here on other streams (e.g., different land use, bedrock characteristics) with higher number of observations where different dominant catchment processes may control the sediment transport. In addition, there is a possibility to also use the approach in hydraulic- 
driven systems where flow forces are acting, shaping the channel bed, and where physiographic factors are less important than in slope-driven systems. A comparison between hydraulic-driven systems and slope-driven systems with data-mining techniques according to sediment transport is not reported in the literature, according to the authors' knowledge.

In hydraulic-driven systems, we would have to identify different parameters describing river channel-flow interactions as potential input variables. Linear models identified by the M5' algorithm could be used for an explanation of suspended sediment and bedload transport. The most relevant hydraulic information is shear stress. Shear stress can be determined by monitoring water depth at longitudinal distances. We also expect that factors like riverbank stability during different seasons (e.g., riverbank vegetation/no riverbank vegetation, freezing and thawing of river bank material) are important for the understanding of transport characteristics in hydraulic-driven systems. Furthermore, in systems controlled by fluvial activity we can use linear models identified by the M5' algorithm to assess information on particle sizes and particle shapes that are being transported. Preliminary investigations in the local Moselle River $\left(23,777 \mathrm{~km}^{2}\right)$ have shown a tendency that coarse and angular bedload materials are transported during the rising limb of the flood wave and round and/or smaller bedload particles are transported during the falling limb (Krein et al. 2008).

There are other factors that are supposed to be similar for slope-to-catchment driven systems and for hydraulic-driven systems; mainly hydrological controls, often determined by the timing and magnitude of hydrograph components, meteorological forcings like air temperature, rainfall depth and intensity, or intra-storm rainfall patterns are of relevance in both systems. Furthermore, we expect that antecedent hydro-climatological conditions before flood events influence bedload and suspended sediment fluxes in both systems. In order to evaluate the influence of antecedent hydrological conditions in hydraulic-driven systems, the concentrations and loads transported by single flood events have to be linked to parameters that are sufficiently described by the situation prior to the event. These may comprise, for example, the maximum water level, discharge or shear stress some days prior to the events under investigation, the pre-rain or the number of storms prior to the event.

\section{Conclusions}

Our study highlights the dominant antecedent hydrometeorological conditions acting as the major controls on the magnitude of SSCs during episodic events in the headwater Huewelerbach catchment in Luxembourg. The main conclusions from our study can be summarized as follows:
- SSCs in the small headwater catchment are more related to $Q$ and antecedent runoff volumes than to other variables; the antecedent runoff volume explains well the depletion of sediment;

- Model trees (M5') can become an alternative technique to traditional univariate rating curves. As such, modular modeling can contribute to substantial scatter reduction by constructing specialized local models linearizing a highly non-linear problem with possibly hidden thresholds. M5' trees improve the assessment of sediment yield in cases where high-resolution measurements are not available. The presently available data allow us only to speculate about the existence of a threshold behavior. Nevertheless, it would be an interesting avenue for further research to test our approach in other catchments with distributed sources of sediment.

Acknowledgments This study was supported by the National Research Fund, Luxembourg (PDR-09-057, TR-PHD BFR07-047 and BEDLOAD C11/SR/1158445), and co-funded under the Marie Curie Actions of the European Commission (FP7-COFUND). This study could not have been conducted without the help of François Barnich (laboratory analyses) and Jean-François Iffly (field work), to whom we would like to express our gratitude.

\section{References}

Alexandrov Y, Laronne JB, Reid I (2007) Intra-event and intraseasonal behaviour of suspended sediment in flash floods of the semi-arid northern Negev, Israel. Geomorphology 85:85-97

Asselman NEM (2000) Fitting and interpretation of sediment rating curves. J Hydrol 234:228-248

Bača P (2008) Hysteresis effect in suspended sediment concentration in the Rybáryk basin, Slovakia. Hydrolog Sci J 53:224-235

Bhattacharya B, Solomatine DP (2005) Neural networks and M5' model trees in modelling water level-discharge relationship. Neurocomputing 63:381-396

Blöschl G, Zehe E (2005) On hydrological predictibility. Hydrol Process 19:3923-3929

Bowes MJ, Williams AH, Hodgkinson RA (2003) Phosphorus dynamics along a river continuum. Sci Total Environ 313:199-212

Bowes MJ, Smith JT, Neal C (2009) The value of high-resolution nutrient monitoring: a case study of the River Frome, Dorset, UK. J Hydrol 378:82-96

Buck O, Niyogi DK, Townsend CR (2004) Scale-dependence of land use effects on water quality of streams in agricultural watersheds. Environ Pollut 130:287-299

Buttle JM, Lister SW, Hill AR (2001) Controls on runoff components on a forested slope and implications for $\mathrm{N}$ transport. Hydrol Process 15:1065-1070

Butturini A, Gallart F, Latron J, Vazquez E, Sabater F (2006) Cross-site comparison of variability of DOC and nitrate c-q hysteresis during the autumn-winter period in three Mediterranean headwater streams: a synthetic approach. Biogeochemistry 77:327-349

Chapman TG, Maxwell A (1996) Baseflow separation - comparison of numerical methods with tracer experiments. Institute Engineers Australia National Conference. Publ. 96/05, pp 539-545

Christopher SF, Mitchell MJ, McHale MR, Boyer EW, Burns DA, Kendall C (2008) Factors controlling nitrogen release from two 
forested catchments with contrasting hydrochemical responses. Hydrol Process 22:46-62

Cobaner M, Unal B, Kisi O (2009) Suspended sediment concentration estimation by an adaptive neuro-fuzzy and neural network approaches using hydro-meteorological data. J Hydrol 267:52-61

De Sutter R, Verhoeven KA (2001) Simulation of sediment transport during flood events: laboratory work and field experiments. Hydrol Sci J 46:599-610

Drewry JJ, Newham LTH, Croke BFW (2009) Suspended sediment, nitrogen and phosphorus concentrations and export during stormevents to the Tuross estuary, Australia. J Environ Manag 90:879-887

Eckhardt K (2005) How to construct recursive digital filters for baseflow separation. Hydrol Process 19:507-515

Eckhardt K (2008) A comparison of baseflow indices, which were calculated with seven different baseflow separation methods. J Hydrol 352:168-173

Evans DJ, Johnes PJ, Lawrence DS (2003) Suspended and bed load sediment transport dynamics in two lowland UK streams - storm integrated monitoring. 283, IAHS, Wallingford, UK, pp 103-110

Francke T, López-Tarazón JA, Schröder B (2008) Estimation of suspended sediment concentration and yield using linear models, random forests and quantile regression forests. Hydrol Process 22:4892-4904

Gerrits AMJ, Pfister L, Savenije HHG (2010) Spatial and temporal variability of canopy and forest floor interception in a beech forest. Hydrol Process 24(21):3011-3025

Hicks DM, Gomez B, Trustrum NA (2000) Erosion thresholds and suspended sediment yields, Waipaoa River Basin, New Zealand. Water Resour Res 36:1129-1142

Horowitz AJ (2003) An evaluation of sediment rating curves for estimating suspended sediment concentrations for subsequent flux calculations. Hydrol Process 17:3387-3409

Ide J, Nagafuchi O, Chiwa M, Kume A, Otsuki K, Ogawa A (2007) Effects of discharge level on the load of dissolved and particulate components of stream nitrogen and phosphorus from a small afforested watershed of Japanese cypress (Chamaecyparis obtuse). J Forest Res 12:45-56

Ide J, Haga H, Chiwa M, Otsuki K (2008) Effects of antecedent rain history on particulate phosphorus loss from a small forested watershed of Japanese cypress (Chamaecyparis obtuse). J Hydrol 352:322-335

Jain SK (2001) Development of integrated sediment rating curves using ANNs. J Hydraul Enging ASCE 127:30-37

James AL, Roulet NT (2009) Antecedent moisture conditions and catchment morphology as controls on spatial patterns of runoff generation in small forest catchments. J Hydrol 377:351-366

Juilleret J, Iffly JF, Hoffmann L, Hissler C (2012) The potential of soil survey as a tool for surface geological mapping: a case study in a hydrological experimental catchment (Huewelerbach, GrandDuchy of Luxembourg). Geol Belg 15:36-41

Kisi O, Karahan EM, Sen Z (2006) River suspended sediment modelling using a fuzzy logic approach. Hydrol Process 20:4351-4362

Krein A, Klinck H, Eiden M, Symader W, Bierl R, Hoffmann L, Pfister L (2008) Investigating the transport dynamics and the properties of bed load material with a hydro-acoustic measuring system. Earth Surf Process Landforms 33:152-163

Lamb R, Beven KJ (1997) Using interactive recession curve analysis to specify a general catchment storage model. Hydrol Earth Syst Sci 1:101-113

Le Bissonnais Y, Singer M (1992) Crusting, runoff and erosion response to soil water content and successive rainfalls. Soil Sci Soc Am J 56:1898-1903

Li RH, Belford GG (2002) Instability of decision tree classification algorithms. KDD '02 Proceedings of the eighth ACM SIGKDD international conference on knowledge discovery and data mining. doi: $10.1145 / 775047.775131$
López-Tarazón JA, Batalla RJ, Vericat D, Francke T (2011) The sediment budget of a highly dynamic mesoscale catchment: the River Isábena. Geomorphology 138:15-28

Macrae ML, English MC, Schiff SL, Stone M (2010) Influence of antecedent hydrologic conditions on patterns of hydrochemical export from a first-order agricultural watershed in Southern Ontario, Canada. J Hydrol 389:101-110

Martínez-Carreras N, Udelhoven T, Krein A, Gallart F, Iffly JF, Ziebel J, Hoffmann L, Pfister L, Walling DE (2010a) The use of sediment colour measured by diffuse reflectance spectrometry to determine sediment sources: application to the Attert River catchment (Luxembourg). J Hydrol 382:49-63

Martínez-Carreras N, Krein A, Udelhoven T, Gallart F, Iffly JF, Hoffmann L, Pfister L, Walling DE (2010b) A rapid spectral reflectance-based fingerprinting approach for documenting suspended sediment sources during storm runoff events. J Soils Sediments 10:400-413

Martínez-Carreras N, Krein A, Gallart F, Iffly JF, Pfister L, Owens PN (2010c) Assessment of different colour parameters for discriminating potential suspended sediment sources and provenance: a multi-scale study in Luxembourg. Geomorphology 118:118-129

McDowell RW, Sharpley AN (2002) The effect of antecedent moisture conditions on sediment and phosphorus loss during overland flow: Mahantango Creek catchment, Pennsylvania, USA. Hydrol Process 16:3037-3050

Mianaei SJ, Keshavarzi AR (2010) Prediction of riverine suspended sediment discharge using fuzzy logic algorithms, and some implications for estuarine settings. Geo-Mar Lett 30:35-45

Nadal-Romero E, Regüés D, Latron J (2008) Relationships among rainfall, runoff, and suspended sediment in a small catchment with badlands. Catena 74:127-136

Nathan RJ, McMahan TA (1990) Evaluation of automated techniques for baseflow and recession analysis. Water Resour Res 26:14651473

Ollesch G, Sukhanovski Y, Kistner I, Rode M, Meissen R (2005) Characterization and modelling of the spatial heterogeneity of snowmelt erosion. Earth Surf Process Landforms 30:97-211

Owens PN, Walling DE (2002) The phosphorus content of fluvial sediment in rural and industrialised river basins. Water Res 36:685-701

Petticrew EL, Krein A, Walling DE (2007) Evaluating fine sediment mobilization and storage in a gravel-bed river using controlled reservoir releases. Hydrol Process 21:198-210

Quinlan JR (1992) Learning with continuous classes. In: Adams, Sterling (eds) Proceedings AI'92. World Scientific, Singapore, pp 343-348

Rusjan S, Mikoš M (2008) Assessment of hydrological and seasonal controls over the nitrate flushing from a forested watershed using a data mining technique. Hydrol Earth Syst Sci 12:645-656

Sadeghi SHR, Mizuyama T, Miyata S, Gomi T, Kosugi K, Fukushima T, Mizugaki S, Onda Y (2008) Determinant factors of sediment graphs and rating loops in a reforested watershed. J Hydrol 356:271-282

Schleppi P, Walder PA, Stähli M (2006) Errors of flux integration methods for solutes in grab samples of runoff water, as compared to flow-proportional sampling. J Hydrol 319:266-281

Schreier H, Brown S (2004) Multiscale approaches to watershed management: land-use impacts on nutrient and sediment dynamics. In: Scales in Hydrology and Water Management/Echelles en Hydrologie et Gestion de l'Eau, IAHS Publ. 287, IAHS, Wallingford, UK, pp. 61-75

Seeger M, Errea MP, Begueria S, Arnaez J, Marti C, Garcia-Ruiz JM (2004) Catchment soil moisture and rainfall characteristics as determinant factors for discharge/suspended sediment hysteresis loops in a small headwater catchment in the Spanish Pyrenees. J Hydrol 288:299-311 
Sichingabula HM (1998) Factors controlling variations in suspended sediment concentrations for single-valued sediment rating curves, Fraser River, British Columbia, Canada. Hydrol Process 12:1969-1894

Solomatine DP, Dulal KN (2003) Model tree as an alternative to neural network in rainfall-runoff modeling. Hydrol Sci J 48:399-411

Solomatine DP, Siek MB (2006) Modular learning models in forecasting natural phenomena. Neural Networks 19:215-224

Solomatine DP, Maskey M, Shrestha DL (2008) Instance-based learning compared to other data-driven methods in hydrological forecasting. Hydrol Process 22:275-287

Štravs L, Brilly M (2010) Development of a low-flow forecasting model using the M5' machine learning method. Hydrol Sci J $52: 466-477$

Tayfur G (2002) Artificial neural networks for sheet sediment transport. Hydrol Sci J 47:879-892

Ternat F, Boyer P, Anselmet F, Amielh M (2008) Erosion threshold of saturated natural cohesive sediments: modeling and experiments. Water Resour Res. doi:10.1029/2007WR006537

van den Bos R, Iffly JF, Matgen P, Salvia M, Hoffmann L, Tosheva Z, Kies T, Pfister L (2004) Constraining conceptual rainfall-runoff responses by incorporating imprecise tracer data information into the calibration process. Proceedings of the "ERB 2004
Conference: Progress in surface and subsurface water studies at the plot and small basin scale", pp 182-185

Walling DE (1977) Limitations of the rating curve technique for estimating suspended sediment loads, with particular reference to British rivers. Proceedings of the "Paris Symposium: Erosion and solid matter transport in inland waters", IAHS Publ. 122, pp 34-48

Withers PJA, Jarvie HP (2008) Delivery and cycling of phosphorus in rivers: a review. Sci Total Environ 400:379-395

Witten ICH, Frank E (2005) Data mining - practical machine learning tools and techniques. Elsevier. 2nd edition, ISBN-13:978-0-12088407-0, pp 243-254

Wood PA (1977) Controls of variation in suspended sediment concentrations in the River Rother, West Sussex, England. Sedimentology $24: 437-445$

Zabaleta A, Martínez M, Uriarke JA, Antigüedat I (2007) Factors controlling suspended sediment yield during runoff events in small headwater catchments of the Basque Country. Catena 71:179-190

Zehe E, Sivapalan M (2009) Threshold behaviour in hydrological systems as (human) geo-ecosystems: manifestations, controls, implications. Hydrol Earth Syst Sci 13:1273-1297 